absolute acceptance of definite items of faith as a preliminary condition to progress. I believe I can safely say that to many minds this is an impossible demand. Conviction of the truth of any faith, so far as a man can measure the truth, is to be gained by practice, and it is here that the scientist finds an illustration in his own work. Every man, in the circle in which he finds himself, it may be a small circle, his means may be small also, can try the Christian way, and discover for himself and acquire his own convictions. He tests his faith. He has ever in front of him the hope that he will by doing his service play his part in binding the community together."

Speaking of his own youth, Sir William writes :

"What we boys asked was the meaning of the word 'believe' when it so often laid down a condi- tion which must be satisfied before a man could be 'saved'. '. . . they that have done evil into everlasting fire. This is the Catholick Faith: which except a man believe faithfully he cannot be saved'. Had we passed the test, or had we not? We were terrified by the threatened consequences. To the youth daily instructed in the need for accuracy and the careful interpretation of words, this was indeed a dreadful saying. If anyone took them at their face value, drew them towards him and explored their significance he would necessarily be driven mad, unless indeed he was deprived of feeling by some drug."

It is a pity that the zeal of the theologian should have converted his "absolute presuppositions" into a barbed-wire entanglement menacing the pilgrim who would explore his temple.

\title{
PSYCHOLOGICAL EFFECTS OF AIR RAIDS
}

\section{By Dr. Robert H. Thouless}

\section{UNIVERSITY OF CAMBRIDGE}

$\mathrm{T}^{\mathrm{H}}$ HE experiences of war through which Great Britain is passing pose many psychological problems of urgent practical importance. Knowledge has been gained in many directions which can now be put to practical use. Detailed studies of evacuation, such as the Cambridge Evacuation Survey, the findings of which have recently been published*, enable us to assess both the general success of the evacuation policy and the particular steps which must be taken to avoid failure in special cases. The problems of shelter life have been studied by medical men, by psychiatrists, by shelter lecturers, and by psychologists who have lived in shelters because they. have been bombed out of their homes, and it is now possible to gain some idea of the iitricate social psychological problems of shelter life. The effects on morale of air-raid experiences have been studied both by academic psychologists and by mass observation, and it is to be hoped that their findings may be made use of by those Government departments responsible for civil morale. These problems were considered at a discussion of the problems of air-raid shelters, evacuation and the effects of air raids at a general meeting of the British Psychological Society on July 26.

Psychologists and psychotherapists have approached the problem of shelter conditions from

* The Cambridge Evacuation Survey. Edited by Dr. Susan Isaacs. Pp. ix +236 . (London: Methuen and Co., Ltd., 1941.) 8s. 6d. net. many different angles; the problems for future research have been clarified and some knowledge has been gained which can be made the basis for practical proposals. The transfer of authority attitudes from within the family to the officials of shelter groups (shelter marshals, etc.) was suggested as an important factor in determining whether defence mechanisms against raid shock would be adequate. It was noticed that a greater sense of security was given by underground shelters than by surface shelters and that the presence of crowds and of the various shelter officials also reduced anxiety. For both of these reasons, individual Anderson shelters were generally neglected and communal underground shelters were preferred. Of those who went to communal shelters, 95 per cent were reported to have got adequate sleep ; weight lost at home was regained and neurotic symptoms disappeared. It seems clear, therefore, that the provision of communal shelters rather than of individual ones is, in general, the best policy.

Studies of those who went through air raids as children in the War of 1914-18 showed the importance of adult attitudes of mental calm as a means of protecting children against raid anxiety, and also the reduction of fear by the provision of suitable spontaneous activities. While lectures on such subjects as first aid have been provided for adults and adolescents in some areas, 
it may be suggested that more ef:ort should be made by those responsible for shelter policy to provide apparatus for suitable activities generally and particularly for children. One area was described in which shelter provision was very inadequate when raids started and a generally apathetic and inert attitude was found among the shelterers. There was little activity; some knitted, few read. Co-operative activity under a leader did not generally develop spontaneously; but when a suitable leader was chosen, the amenities of the shelter were greatly improved by co-operative effort. In one shelter, the selection of a good leader resulted in Oxo service, lectures and Christmas decorations, whereas there had previously not been even a broom to sweep the shelter clean.

The problem of the evacuation of children less than five years of age was one that aroused great interest and keen discussion. The general undesirability of evacuating children of this age without their mothers was recognized. On the other hand, it was pointed out that mothers of young children are now often doing war work and that the choice might be between adequate care away from the mother and neglect at home. It was also mentioned that experience at hostels for young children has shown that many of those evacuated from badly bombed areas show neurotic symptoms and unsatisfactory relations with their mothers, and that a period of separation from their mothers in a hostel produces marked improvement in both respects. Some of those present at the meeting consider that a foster-home is more suitable for a young child than a hostel if separation from the mother is necessary or desirable. Other solutions of the problem were mentioned. The Society of Friends has hostels for young children accompanied by their mothers, but these experience the difficulties that have been found in all plans for evacuation of mothers. The mothers do not wish to desert their husbands. A plan that was reported to have been very successful where it has been tried is the provision of nursery centres where children can be left while their mothers are at work. The children may be anxious at first, fearing that their mothers will not return to fetch them in the evenings, but when the experience of a few days proves that this fear is unfounded the children become very happy and contented in the centres. As an alternative to evacuation, this plan suffers obviously from the disadvantage that it may mean that young children remain in danger areas exposed to the risk of physical injury and that this risk must be balanced against the danger of mental injury through separation from the mother.

The general feeling of the meeting seemed to be that evacuation of the mother and young child together is the ideal solution, but that since cir- cumstances might make this impracticable and even in some cases undesirable, psychologists should be prepared to advise alternative methods in particular cases.

One of the defects of the original arrangements for evacuation found in many districts was the lack of provision for those children whose behaviour problems are such as to make them an intolerable burden to the ordinary householder. In many places hostels are provided for such children, but many of these hostels were and still are by no means suitable for this purpose. Some of those present described bad hostels, unsuitably equipped and staffed, where the staff have no idea whatever of the problem child's difficulties or how these might be treated, and where the incidence of certain problems (such as enuresis) is made unnecessarily high by unsympathetic treatment. One speaker described an ideal hostel for treatment at Aylesbury which is housed, equipped, staffed and managed with the aim of relieving the problem child of the burden of his problems. Elsewhere psychological clinics have done excellent work among problem children although the combination of climic with hostel for treatment appears to be the ideal where practicable.

It is generally felt that a satisfactory hostel is one which makes provision for treatment and is not merely a dumping ground for problem children. There is, no doubt, also a place for the hostel which is merely a clearing house for children who have billeting difficulties, but billeting in such a hostel should be regarded as only a preliminary to treatment. It is felt that psychologists are now in a position to state the requirements of a treatment hostel in equipment and staff, and it was agreed at the meeting that such a statement should be made.

It is not unlikely that the ideal requirements of the social psychologist in provision for problem children will not be met on grounds of expense. It must be remembered, however, that we now have unique opportunities of dealing with the problems of maladjusted children at an early stage and that the provision of reformatories and prisons for the maladjusted members of the community is also a heavy expense to the community.

Investigations in heavily raided areas other than London seem to show that, although morale was in general good, there were failures of morale and a definite tendency for it to deteriorate, particularly in areas which had a number of heavy raids with long periods of calm between them. Deterioration of morale was shown by unauthorized and unnecessary evacuation, general depression about the War, and criticism of the Government. It was interesting to notice that while people in the most 
heavily raided areas were more critical and depressed, they were nevertheless more active in A.R.P. work and saved more money than in less raided areas. They were also more inclined to reject the idea that we should undertake reprisal raids on German towns.

The necessity was pointed out of confidence (and justified confidence) in the shelter provided. In some areas shelters have been unsafe, with bad psychological effects. The possibility was pointed out that even where there are no dramatic failures to stand up to bombing (such as psychoneuroses), there might be long-term effects which were little noticed at the time, and that morale might become worse during this winter. It is necessary that there should be propaganda directed towards the strengthening of morale and that psychologists should play a part in the development of a morale policy.

One possible effect of war conditions which has aroused some concern is their influence on the education of children. It is disturbing to learn that, in Glasgow, achievement tests showed that, in one subject (reading), children were on the average about one year behind mean school level. It is also suggested that the situation may be worse in areas which have been raided over a longer period than Glasgow. On the other hand, there must be a considerable proportion of children in reception areas whose education has been relatively little retarded. It seems very desirable that there should be more extensive studies directed towards discovering the amount of educational retardation in different areas and the proportion of children showing marked educational retardation, and if this is found to be generally serious that steps should be taken to prevent the matter from becoming worse. Many of the advantages of universal education and the additional advantages hoped for through a raising of the school-leaving age will be lost if there is continued educational retardation through enemy action.

\title{
SOLID CARBON DIOXIDE AS AN EXCITER OF VIBRATIONS
}

\author{
By Mary D. Waller \\ LONDON (R.F.H.) SCHOOL OF MEDICINE FOR WOMEN
}

TT is well known that solid carbon dioxide produces noises or squeaks when it is brought into contact with metal objects such as a hammer or chisel, and so long ago as 1932 the fact that a bicycle bell could be made to emit a chattering ring by touching it with the material was brought to my notice by an itinerant vendor of ice-creams ${ }^{1}$. This strange phenomenon has since been investigated very thoroughly and the results published in a number of papers ${ }^{2}$. As the solid carbon dioxide method of producing vibrations is in certain respects unique and can be applied to various problems, it seems desirable that a short account of it should be put on record.

\section{Production and Maintenance of Pure LOUd TONES}

When a tuning-fork of ordinary pitch is touched with solid carbon dioxide, a chattering noise is produced. When glass is touched there is no sound. When, however, a fork of say 2000-3000 c./sec. is tried, provided the contact between the two solids is light and the area of contact small, an intense pure note may be produced and main- tained for several minutes. The demonstration of this phenomenon is very striking.

Quality of the Exciter. Compressed 'snow' solid carbon dioxide is not satisfactory. A high density 'ice' variety, such as 'Drikold', which is manufactured by Imperial Chemical Industries, Ltd., may be recommended. The material may be conveniently stored for some days in a large thermos flask, and handled with lined gloves or a piece of flannel or tweezers. It may be broken up, so as to obtain suitable pointed pieces, by means of a hammer and chisel.

Nature of the Vibrating Object. Tuning-forks, suspended brass bars, tubes, rings and metal plates are easily set into vibration, since they are good thermal conductors and possess adequate vibrating properties (see also below).

External Conditions. The atmosphere must be dry. Excitation may be rendered independent of the hygroscopic conditions by gently warming the vibrating object and surrounding air by means of a bowl electric radiator, care being taken that the heat is not sufficient to alter either the elastic or damping properties of the material of the object.

Manipulation. It is very important that the 